\title{
O modernismo e suas abordagens em Moçambique e Angola
}

\author{
Modernism and its approaches in Mozambique and Angola
}

Rui Paes Mendes

Geógrafo, doutor em Geografia Humana, investigador do Centro de Estudos e Ordenamento do Território (CEGOT), Faculdade de Letras da Universidade do Porto, Porto - Portugal, e-mail: ruipaesmendes@gmail.com

\section{Resumo}

A ditadura portuguesa condicionou a vida de Portugal durante grande parte do séc. XX, procurando regular todos os sectores da vida portuguesa à vontade do Estado, indo sua intervenção até a uma imposição do gosto e da estética dos seus cidadãos que se refletiram na arquitetura e no urbanismo. Os arquitetos portugueses, inicialmente conformados a uma política de encomenda do Estado Novo, vêm a ser influenciados com o advento do modernismo, com forte impacto junto às novas gerações de arquitetos que se formam na década de 1940. A nova visão preconizava que a arquitetura deveria aproximar-se dos anseios do cidadão, numa linguagem internacional que conduziria à própria reorganização da cidade. Essa visão é fortemente influenciada pela produção arquitetónica brasileira, que se revelaria essencial, pois do ponto de vista climático era muito semelhante ao continente africano, existindo diversas soluções e técnicas já experimentadas e saberes sedimentados que poderiam ser transpostos para aquele contexto. Até a independência, as colónias portuguesas experimentam um conjunto de intervenções arquitetónicas e urbanísticas influenciadas pelo modernismo brasileiro. Com a independência, a generalidade dos arquitetos regressa a Portugal, introduzindo novas contribuições estilísticas na paisagem urbana portuguesa, mas alguns partem (também) para o Brasil, estabelecendo sua atividade naquele país.

Palavras-chave: Modernismo. Urbanismo. Arquitectura. Colonialismo. África.

\section{Abstract}

During most of the 20th century, Portuguese dictatorship conditioned the life of Portugal looking to regulate all sectors of Portuguese life to the will of the state, including an imposition of aesthetics in landscape and life of its citizens as reflected in architecture and urbanism. The Portuguese architects initially were submitted to a policy of the State, became influenced by modernism, with strong impact on new generations of architects from (19)40. The new vision advocated that architecture should approach the aspirations of citizens in a international language that lead to the reorganization of the city itself. This view is strongly influenced by 
Brazilian architectural production that has proven ideal to the climatic characteristics, very similar to that in the African continent, where several solutions and techniques were tested and sedimented. Until the independence, Portuguese colonies experienced a set of architectural and urban interventions influenced by Brazilian modernism. With the independence the majority of architects returned to Portugal introducing new stylistic contributions in Portuguese urban landscape but some went (also) to Brazil establishing its activities in that country.

Keywords: Modernism. Urbanism. Architecture. Colonialism. Africa.

\section{A consolidação de processos no espaço colonial africano: das encomendas de Estado à reacção modernista}

O espaço colonial português e suas abordagens territoriais

0 entendimento da arquitectura modernista na África portuguesa é compreensível como uma reacção a uma prática de arquitectura e urbanismo defendida e implementada pela ditadura portuguesa que conduziu os destinos do Estado (e suas colónias) de 1926 a 1974. Essa concepção estatal, que bebia influências em vários países e colónias, construiu um imaginário formal imperial pouco dinâmico que reproduzia um mesmo modelo de "fazer" a cidade e era idêntico independentemente do espaço geográfico do imenso império português ${ }^{1}$, mas que teve nas parcelas africanas - territórios urbanisticamente (quase) virgens - o palco ideal para sua concretização.

Todo o processo era submetido à vontade do Estado, em Lisboa: desde a localização (nos novos aglomerados que foram sendo construídos durante a ditadura) até os projectos, arquitectos, engenheiros, etc., pouco sobrando para uma concepção livre e imaginativa, pese embora em África, em virtude da distância de Lisboa e vizinhança das colónias com outras realidades coloniais (francesa, belga e britânica), existisse maior liberdade formal do que na metrópole. A partir de 1948, dá-se uma reacção a esse tipo de arquitectura, conduzida por uma geração que tinha sido influenciada pelo CIAM e princípios de Le Corbusier. Esses jovens arquitectos seguiam e admiravam os arquitectos modernistas brasileiros, fazendo leitura e interpretação atenta do imaginário modernista que se produzia no Brasil. Em face da resistência, quase negação, na sociedade e poderes políticos de Lisboa ao advento dessas ideias, muitos desses arquitectos embarcam (ou regressam) a África, considerando ali existirem mais oportunidades para praticarem arquitectura livre dos espartilhos ditatoriais de uma arquitectura imperial e regionalista.

O espaço africano contava com um número muito reduzido de aglomerados, pois seu povoamento e sua estruturação territoriais foram muito tardios, ante os espaços do subcontinente indiano e brasileiro. Durante vários séculos, para Portugal, África pouco mais representava do que porto de escala e/ ou abrigo nas viagens de travessia dos oceanos para oeste e leste; complementarmente era alfobre de riquezas como os escravos e o marfim. A prioridade assentava noutras paragens coloniais: a sombra das riquezas provenientes das índias e dos brasis impede uma valorização sustentada e coerente nos territórios africanos, influenciando a forma como se construíam os aglomerados urbanos, que, com raras excepções, eram manifestamente precários.

\footnotetext{
1 0 "império" colonial português era vasto e compreendia territórios em diversos continentes: na Europa, Portugal continental, Açores e Madeira; em África, Cabo Verde, Guiné-Bissau, S. Tomé e Principe, S. João Batista de Ajudá, Cabinda, Angola, Moçambique; na Ásia, Estado português da Índia (Goa, Damão e Diu), Macau e Timor. Dessa diversidade territorial resulta igualmente uma diversidade cultural com implicações na forma de se "construir" a cidade, pois existiam colónias (Ásia) com um saber milenar na sua construção e às quais os portugueses se adequaram, e outras (África) onde quase não existiam preexistências urbanas. Dessa forma, apesar de existir uma linguagem comum reconhecível na paisagem urbana, existem adaptações decorrentes da ancestralidade cultural dos espaços.
}

urbe. Revista Brasileira de Gestão Urbana (Brazilian Journal of Urban Management), v. 4, n. 2, p. 245-257, jul./dez. 2012 
A valorização urbana do espaço africano português

A partir da independência do Brasil, compreende-se a necessidade de valorizar as possessões africanas, projecto sucessivamente adiado em virtude de instabilidades políticas de Lisboa, crises económicas e guerras civis. No entanto, a partir de 1885, com a Conferência de Berlim, que obrigava a uma ocupação efectiva do território é que os portugueses (e restantes potências) iniciam a ocupação do interior do continente, seleccionando os locais estratégicos para o aglomerado e construindo-o. Foi um período de actividade científica e construção urbana intensas, que transformariam as cidades africanas em palcos para a aplicação de soluções urbanas modernas e de demonstração de poderio por meio da construção de uma imagética urbana muito própria.

A lógica na selecção dos sítios assentava primordialmente em escolhas de carácter estratégico e, quando possível, conciliando o factor comercial e militar: o primeiro, para garantir as necessidades da metrópole, enquanto que o segundo procurava submeter os indígenas e a segurança dos colonos e das rotas/abastecimentos comerciais. Dessa forma, esse primeiro impulso estruturado de transformação urbana do espaço é orientado pelo Estado, "seja na definição dos novos assentamentos - após missões de reconhecimento para o qual muito contribuiu a Sociedade de Geografia de Lisboa -, seja na regulação da forma e recursos desse mesmo assentamento" (MENDES, 2012, p. 188).

Genericamente, essa primeira abordagem do Estado português às questões do urbanismo na África portuguesa segue de perto a tendência das restantes potências coloniais que na época tinham uma prática assente no modelo ortogonal. É de sublinhar, de resto, que a atracção pelo segmento de recta não era exclusivo do espaço africano, sendo igualmente replicado em escalas diferentes e condicionalismos diversos ditados pelo espaço disponível, relevo e preexistências urbanas. É igualmente importante sublinhar que durante o séc. XIX e o início do séc. XX, as intervenções na malha urbana de aglomerados urbanos existentes no Ultramar estavam sob alçada dos engenheiros militares, em virtude de um espírito de "cerco e de conquista no qual assentava a colonização portuguesa, assim como o facto, de que os territórios ultramarinos não seriam atractivos para um conjunto de técnicos ainda insuficientes para Portugal Continental" (MENDES, 2012, p. 189).

Uma análise atenta entre as plantas da metrópole e as das colónias africanas não detecta ruptura entre a prática vigente em Portugal, ou mesmo do resto da Europa, e o que se fazia em África, onde imperava uma tendência de se ampliar as urbes ou reconfigurá-las tendo por base o segmento de recta, algo que é perceptível comparando-se a planta de uma urbe no contraste entre o seu núcleo e a sua periferia. Na metrópole, como nas colónias, os engenheiros militares desempenhavam papel activo na intervenção no corpo urbano, mesmo após a criação das Escolas Politécnicas de Lisboa e do Porto, em 1837 (FERNANDES, 2001, p. 77). Essas plantas assumiam valor jurídico imprescindível, quer para os actores públicos, quer para os privados, pois "era preciso possuir uma planta de valor legal para dividir em parcelas o espaço destinado às habitações, distinguindo-o daquele para uso público, como ruas e praças" (BRUSCHI; LAGE, 2005, p. 26). A planta ortogonal nesses territórios caracteriza-se pelo uso de um bloco compacto de quarteirões, separados uns dos outros e limitados por estradas sempre da mesma largura. Os quarteirões são divididos em talhões, que nesse período inicial eram de preferência quadrados, sendo que a ausência de um quarteirão em posição central representava a 'praça' (BRUSCHI; LAGE, 2005, p. 26-27).

Essa é a matriz dos aglomerados urbanos nas colónias africanas que, mesmo nos casos em que existiam preexistências urbanas de outros períodos, normalmente de reduzidas dimensões - como é o caso de Lourenço Marques/Maputo no que respeita a seu núcleo antigo ou o de Luanda -, é predominante na sua envolvente. Uma das poucas excepções a esse tipo de assentamento ortogonal acontece na Ilha de Moçambique, mas, nesse caso, preexistências históricas e culturais, assim como constrangimentos geográficos, explicam outro desenho urbano.

0 crescimento dos núcleos urbanos na África Portuguesa, como reflexo de uma valorização territorial geradora de recursos financeiros, permite abordagem diferente na criação do espaço urbano, traduzida numa preocupação com a forma e com o conforto, procedendo-se, então, à incorporação dos normativos legais vigentes em Portugal, a fim de melhorar as condições de habitabilidade (FERNANDES, 
2001, p. 190-191). Em Angola, um plano de Nova Lisboa, de 1912, assenta numa base de cidade-jardim, enquanto que em Moçambique os novos apports estão patentes no caso de Inhambane, com um plano de 1910, no qual era evidente a intenção de se (re)criar uma cidade estilisticamente depurada, em contracorrente a um traçado de índole prática e estilisticamente frugal, apesar de na actualidade se encontrar substancialmente alterado. Há também o projecto surpreendente, e parcialmente concretizado, de Vila Cabral/Lichinga, de 1931-1932, cidade situada junto à fronteira de Moçambique com o Malawi que viu desenhada um plano inspirado no urbanismo utópico renascentista da cidade ideal (Figuras 1 e 2), demonstrando que as influências não tinham fronteiras, aplicando-se em qualquer contexto geográfico.

A implantação da República em Portugal, em 1910, se marca a criação de um novo modelo político e social para a metrópole, é incapaz de desenvolver e implementar um modelo de desenvolvimento colonial fruto da instabilidade política e económica do país, agravada com o envolvimento na Primeira Guerra Mundial, a pretexto de proteger da cobiça de alemães e de britânicos suas colónias de Angola e de Moçambique. Esse conflito leva o Estado português a encetar uma campanha de pacificação dos indígenas que se opunham à autoridade portuguesa e a uma tentativa, limitada por escassez de fundos, de estruturar os territórios por meio do desenvolvimento de redes urbanas e comerciais.

Dessa forma, durante esse período houve algum esforço para se criarem povoados que traduzissem essa ocupação do território (em Moçambique: Namaacha, 1916; Nampula 1920; Massinga, 1916; Mocuba, 1918, por exemplo; em Angola: Huambo/ Nova Lisboa 1912, Vila Robert Williams/Caála, 1912), mas, do ponto de vista cartográfico, não se conhece grande produção no levantamento e documentação dos povoados/aglomerados existentes nem para efeitos de base cadastral.

Em 1926 é imposta uma ditadura militar que cria mitologia própria de um Império Colonial que teria Portugal Continental, ou mais propriamente Lisboa, como principal dínamo de territórios tributários e enfeudados, regulando e determinando todos os sectores da vida do país (e suas colónias) à vontade de um punhado de personalidades que definiam a concepção de fazer arte, de fazer a cidade, de pensar

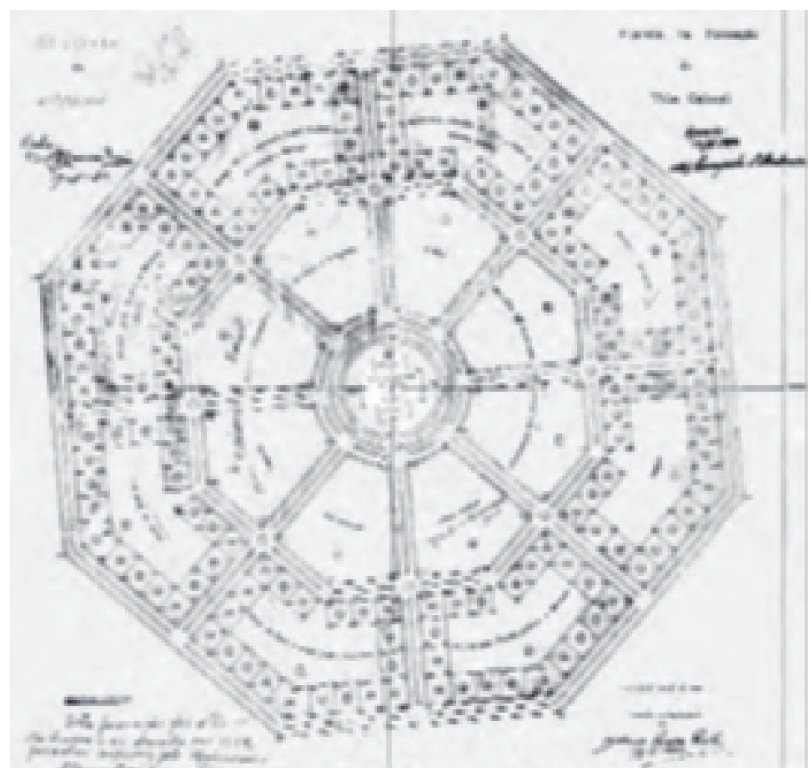

Figura 1 - Planta de Vila Cabral/Lichinga (1931, 1932) Fonte: BRUSCHI; LAGE, 2005.

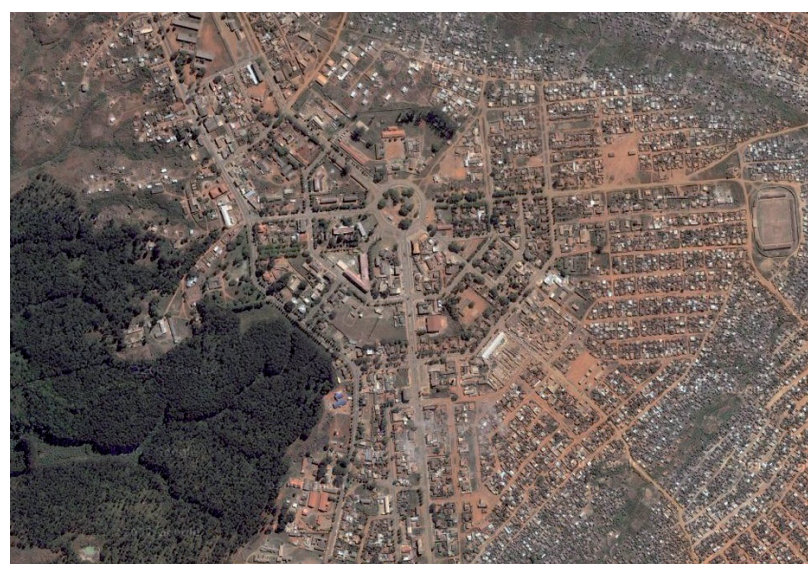

Figura 2 - Imagem de satélite de Lichinga

Fonte: Google Earth, 2011.

o território. A ditadura tem uma preocupação vincada com o(s) território(s), reflectindo em sua acção as preocupações urbanísticas e de ordenamento do território que então surgiam e que eram introduzidos e trabalhados de acordo com a realidade económica e política preconizada para o país.

Na década de 1930, o regime lança vasta política de obras públicas, que visava à infraestruturação e ao reequipamento territorial e que cristalizou uma forma de intervir no espaço. Essa intervenção baseia-se na construção de estradas e disseminação do transporte marítimo e telefone, no sentido de 
articular o território numa tripla vertente: interna, colónias e externa. Nesta última é possível detectar lógica de continuidade e uniformidade na execução dos projectos de equipamentos de que os diversos sectores tivessem necessidade para sua acção governativa (MONIZ, 2005, p. 68-79), marcados, segundo a arquitecta Ana Tostões (1999, p. 524), pela modernidade e a monumentalidade, numa elegante e austera simbiose balançada entre a manipulação de volumes claros e puros, e o frequente recurso a uma composição simétrica, com entradas marcadas por grandes pilastras, escadarias monumentais, pés-direitos múltiplos, revestimentos em mármore e enquadramentos de painéis pictóricos.

\section{O advento do modernismo em Portugal e o impulso na arquitectura e urbanismo colonial}

\section{O reconhecimento da especificidade urbana da África Portuguesa}

Dos projectos do governo à elaboração de um conjunto de regras, muitas vezes informais, mas por todos subentendidas, padronizadas e sistematizadas, discretamente impostas e tacitamente aceites pela maioria dos arquitectos, foi um passo (Figura 3). Apesar de garantir o trabalho a muitos arquitectos portugueses, eles tinham que trocar sua criatividade pelo beneplácito do Estado, traduzido sob a forma de encomendas, sujeitas a uma mesma filosofia e a um ou a uns poucos modelos facilmente reconhecíveis, aplicáveis e replicáveis a qualquer situação ou território.

0 projecto imperial português, no que respeita aos princípios arquitectónicos e urbanísticos, teve sua montra em 1940 com a realização da Exposição do Mundo Português, para a qual foram convidados todos os arquitectos portugueses de nomeada para contribuir para as celebrações e, simultaneamente, requalificar toda uma zona da cidade. Foi um momento importante da propagandística portuguesa $\mathrm{e}$ de sedimentação de uma imagem comum, mas teve igualmente o condão de revelar a carência técnica dos arquitectos envolvidos, pois eles estariam "longe de poder pensar em termos urbanos, em termos de cidade, [...] faltando uma dimensão urbanística para além de implicar uma falta de consciência social [...]" (FERNANDES; ALMEIDA, 1993, p. 123). Essa constatação teve por prerrogativa uma aposta, por parte do governo português, em recrutar urbanistas estrangeiros como Agache, Groer, Piacentini e Muzio para trabalharem o território português ${ }^{2}$, numa acção que viria a marcar a paisagem urbana portuguesa, influenciando arquitectos e engenheiros portugueses e trazendo para o país técnicas e estilos provenientes de países onde a prática da ciência urbanística se encontrava consolidada.

A Exposição do Mundo Português, de 1940, definia a linha que se pretendia implementar em termos arquitectónicos e urbanísticos no território português e ultramar, reduzindo as opções técnicas e estilísticas que existiam nas colónias, e que se faziam sentir em algumas tentativas tímidas de fugir à malha ortogonal e de introduzir alguma ruptura num urbanismo convencional e repetitivo - tentativas que, de resto, iam fazendo escola em alguns projectos pontuais, e de maior escala, como bairros, de que é exemplo o bairro indígena de Lourenço Marques/Maputo (Figura 4) ou mesmo na cidade da Beira (MENDES, 2012, p. 197).

Essas limitações conceptuais cristalizam-se com a criação do Gabinete de Urbanismo Colonial, em 1944, com a incumbência de conduzir as obras

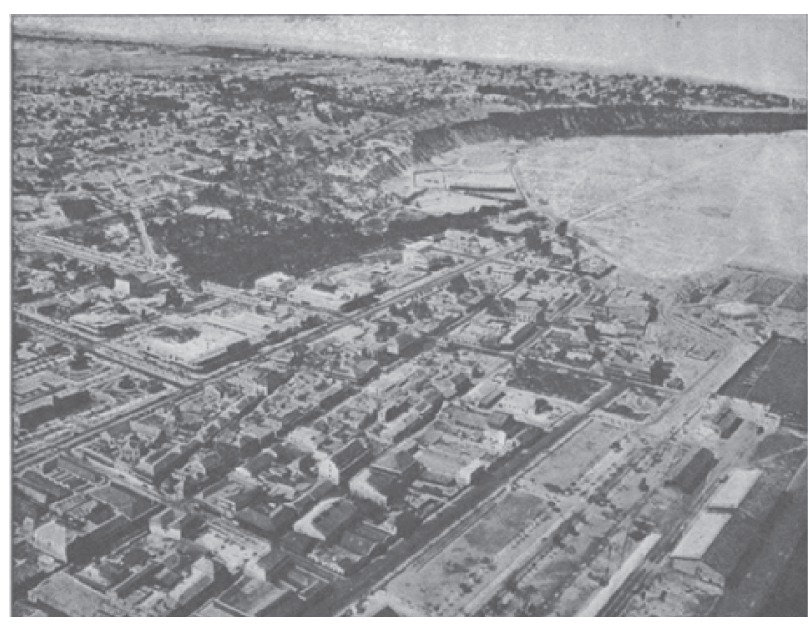

Figura 3 - Vista aérea cidade baixa de Lourenço Marques/Maputo, antigo pântano do Maxaquene urbanizado e área futuramente conquistada ao mar (1935)

Fonte: Moçambique - Documentário Trimestral, 1935.

\footnotetext{
2 Apenas em 1945 surge o primeiro arquitecto português com formação específica em Urbanismo, Faria da Costa.
} 


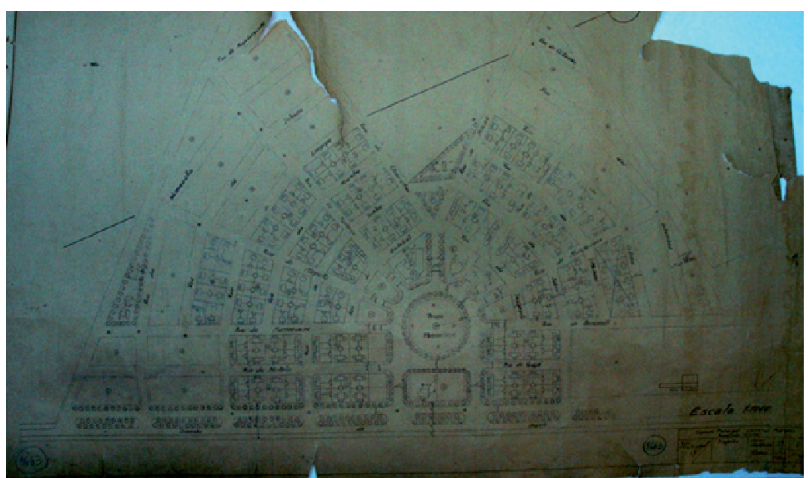

Figura 4 - Planta bairro do indígena de Munhuana (c. 1939) Fonte: Rui Paes Mendes, 2011.

Nota: foto do Arquivo Histórico de Moçambique (não publicado).

públicas e a urbanização das colónias. No entanto, a acção ao nível das obras públicas era complexa, pois o território ultramarino português assentava em realidades sociais diversas que não permitiam uma abordagem homogénea: em África, a ocupação efectiva era recente e desigual com parcelas de território claramente desestruturadas, enquanto que na Ásia, mais concretamente na Índia Portuguesa, os níveis de desenvolvimento eram efectivos e globalmente positivos, assentando o desenvolvimento em núcleos urbanos preexistentes.

Segundo Decreto n. 34.173, cabia ao Gabinete de Urbanização Colonial a importante tarefa de velar pelo crescimento urbano dos territórios, devendo para tal "estudar e acompanhar a formação e o desenvolvimento dos aglomerados populacionais nas colónias de modo a aproveitar os ensinamentos da urbanística, evitando os erros por vezes irremediáveis, de um crescimento ao acaso" (PORTUGAL, 1944), procedendo à execução e acompanhamento das obras públicas adjudicadas nos territórios coloniais. Isso significava claramente que o urbanismo e a arquitectura passavam a ser um instrumento do Estado "na domesticação do espaço e elaboração de uma linguagem colonial que servisse os intentos do controlo do Estado sobre o espaço, garantindo desta forma a sobrevivência do primeiro" (MENDES, 2012, p. 198). 0 urbanismo das cidades coloniais tem carácter imperativo na acção do Gabinete, sendo essencial intervir naqueles espaços, de acordo com Decreto n. 34.173, de 1944, como forma de ultrapassar os "problemas da urbanização colonial e promover a elaboração de planos de arranjo e expansão das cidades e vilas das colónias africanas" (PORTUGAL, 1944). Essa linha levou à realização de Anteplanos de urbanização para a maioria das cidades e vilas das colónias portuguesas ${ }^{3}$.

A centralização do processo de planificação urbana dos espaços coloniais tinha o problema de ser conduzido, a partir de Lisboa, por técnicos com pouco ou nenhum conhecimento da realidade dos territórios para os quais projectavam, obedecendo a ditames políticos, que traduzisse uma forma portuguesa de construir o espaço colonial, mas que atendesse às especificidades climáticas inerentes aos trópicos (MILHEIRO; DIAS, 2009).

Inicia-se uma profunda intervenção no espaço urbano colonial, de acordo com

um modelo que nas áreas centrais das cidades procurava efeitos de monumentalidade através de eixos convergentes ou grandes avenidas lineares, que assumiam uma função estruturante para o inteiro organismo urbano. 0 mesmo modelo, nas áreas residenciais, não menosprezava a utilização de uma composição mais livre, utilizando soluções formais já experimentadas no paisagismo britânico. Em todos os casos, as soluções eram sempre estudadas em pormenor, sendo os planos caracterizados por uma execução gráfica muito cuidada (BRUSCHI; LAGE, 2005, p. 35).

0 princípio atrás enunciando era, nos seus traços genéricos, o mesmo que era prosseguido no Portugal metropolitano, no qual se procedia à construção de uma mitologia simbólica representativa do regime, procurando passar a imagem da supremacia do Estado, da ordem pública e da funcionalidade orgânica da cidade na autorregulação e vigilância de seus cidadãos que, na prática, traduzia-se na implementação de forte zonamento segregacionista, numa atitude de demonstração dos benefícios civilizacionais para os territórios em domesticação (MENDES, 2012, p. 199).

No entanto, essa política de forte intervenção urbana era dispendiosa, não possuindo o Estado

\footnotetext{
3 A exemplo, aliás, do que acontecia no Portugal metropolitano.
} 
português recursos suficientes para intervir na totalidade das parcelas territoriais de que dispunha e nos quais desejava intervencionar, sendo unicamente possível em centros urbanos de média ou grande dimensão, geradores de fluxos financeiros passíveis de pagarem por si mesmos essas obras. Em Moçambique, apenas Lourenço Marques/ Maputo e a cidade da Beira, ou em Angola Luanda, Nova Lisboa/Huambo e o Lobito, estariam nessas condições, enquanto que nos restantes territórios africanos sob domínio português apenas Bissau, na Guiné, enunciava condições para tal. Para os centros de menores dimensões, o modelo seguido apostava numa linha enunciada pelo arquétipo das cidades-jardim, nas quais se sublinhava o contraste dado:

no tratamento das zonas centrais utilizava-se todo o repertório da monumentalidade, mas sublinhando o traçado dos eixos estruturantes com massas vegetais em substituição da frente contínua dos edifícios, enquanto que nas zonas residenciais continuavam a ser utilizados elementos seleccionados do repertório da cidade jardim, como a sinuosidade das ruas, a ênfase na arborização e a fraca densidade (BRUSCHI; LAGE, 2005, p. 36).

Essa disposição possuía ainda a virtude de se constituir como áreas-tampão entre raças e classes sociais, numa estratégia securitária e higienista, de acordo com o que vigorava noutros quadrantes do espaço colonial africano.

Paralelamente, o conhecimento pelas especificidades territoriais das colónias vai-se aperfeiçoando e especializando com visitas de reconhecimento, de acompanhamento, e pela frequência de cursos de arquitectura tropical, em Londres, a técnicos do Gabinete. Este serviu igualmente para diversos jovens arquitectos da linha modernista efectuarem seu tirocínio, levando-os a apreender os conceitos da arquitectura portuguesa de estado antes de embarcarem para África, desenvolvendo trabalhos que se encontravam nos anípodas dos pressupostos estatais.

O desenvolvimento económico (e cultural) das principais colónias portuguesas - Angola e Moçambique -, conjugado com os desenvolvimentos políticos provocados pelo início da Guerra Colonial, provoca uma alteração de paradigma na abordagem efectuada ao território, recaindo a opção por uma descentralização de serviços que tornasse mais célere a acção urbanística e de engenharia civil e, simultaneamente, reconhecesse a especificidade territorial de cada parcela colonial. Nesse contexto, é decretada a extinção do Gabinete de Urbanismo do Ultramar, sendo substituído pela Direcção de Serviços de Urbanização e Habitação, com secção de urbanização específicas para cada território.

\section{A África Portuguesa como destino de uma geração de arquitectos}

Do ponto de vista cultural, a acção de um conjunto de arquitectos influenciados pelo modernismo, teve um impacto importante na conjuntura. Se numa fase inicial geraram resistências junto aos poderes instituídos, acabariam por se aliar com os serviços da administração colonial a requisitar os seus serviços.

A geração modernista começa a ganhar protagonismo com o fim da Segunda Guerra Mundial, momento marcante do ponto de vista das concepções estilísticas ao nível do urbanismo e da arquitectura em Portugal, a partir do qual as ideias veiculadas pelo CIAM - Congrès Internationaux d'Architecture Moderne (IV), em especial nas soluções para a resolução do "problema habitacional" dos estratos com menores recursos, começam a ganhar adeptos junto aos arquitectos mais jovens. 0 ponto de viragem terá sido o I Congresso Nacional de Arquitectura, promovido pelo Sindicato Nacional de Arquitectos, em 1948. Esse Congresso constituiu oportunidade única para a escola mais progressista/modernista expressar-se, debater, trocar ideias, defendendo uma outra concepção de arquitectura para lá da cartilha que uma arquitectura de cariz regionalista e nacionalista imposta pelo Estado para adjudicação das suas encomendas provocava, defendendo que uma nova arquitectura deveria ser prosseguida, mais próxima do mundo real, das vontades e expectativas dos cidadãos, numa linguagem comum internacional que, em seu ponto último, se consubstanciaria na reorganização da cidade.

Igualmente importantes são as conclusões do Congresso que destacam a necessidade de "facilitar o tirocínio de arquitectos nas Colónias, contribuindo para fixar alguns deles no Ultramar, com manifesta vantagem para a arquitectura colonial e para 
o País" (SINDICATO NACIONAL DOS ARQUITECTOS, 1948, p. 147), que vem na esteira da intervenção do arquicteto João Simões:

"A profissão de arquitecto nas colónias", na qual considera estar a acção nas metrópoles limitada, não tendo os arquitectos ali radicados sido capazes de criar uma Arquitectura Funcional, bem resolvida, a que fosse possível chamar a nossa Arquitectura colonial, variada consoante os locais, una quanto às preocupações de melhor defesa das condições de vida humana, quer a do indígena, quer a do colono (SINDICATO NACIONAL DOS ARQUITECTOS, 1948, p. 147).

Se as influências teóricas são bebidas através das publicações internacionais, nomeadamente as resultantes do CIAM, as de índole prática são assimiladas ou inspiradas pela produção arquitectónica brasileira, que encontra como elemento de transmissão a realização de duas exposições de divulgação da arquitectura brasileira que ocorrem em território português.

A primeira ocorreu em data incerta, entre fins de 1948 ou inícios de 1949 (MILHEIRO; FERREIRA, [200-], p. 2), no Instituto Superior Técnico, durante três dias, mas com grande impacto junto a alguns arquitectos, como nos demonstra um texto extremamente elogioso sobre o evento, escrito pelo arquicteto Sebastião Formosinho Sanchez, na revista Arquitectura, em 1949. Esse arquitecto seria um dos responsáveis pelo projecto conhecido como Bairro das Estacas, em Lisboa, que viria a ser premiado na II Bienal do Museu de Arte Moderna de São Paulo, de 1953 (MILHEIRO; FERREIRA, [200-], p. 6).

A segunda exposição sobre arquitectura brasileira realiza-se em 1953, na Sociedade Nacional de Belas Artes, por ocasião do III Encontro da União Internacional de Arquitectos, realizada em Lisboa no Palácio Foz, com um impacto mediático muito maior que a anterior, chegando a muito mais arquitectos e alunos de Arquitectura (MILHEIRO; FERREIRA, [200-], p. 6).

As influências práticas da produção arquitectónica e urbanística brasileira no contexto colonial português revelar-se-iam essenciais, pois, do ponto de vista climático, o Brasil era muito semelhante ao que se podia encontrar na África portuguesa, existindo um conjunto enorme de soluções e técnicas já experimentadas e saberes sedimentados que poderiam ser transpostos com segurança para aquele contexto.

A geração de arquitectos modernistas portugueses embarcam para as colónias portuguesas africanas por diferentes razões: ideológicas ou políticas (como é o caso de Francisco Castro Rodrigues), pela sua naturalidade (como Vasco Vieira da Costa, Fernão Simões de Carvalho ou João Garizo do Carmo), ou simplesmente procurando novas oportunidades (como João José Tinoco, Francisco Castro ou Paulo Melo Sampaio (MAGALHÃES; GONÇALVES, 2009 , p. 18), procurando (e encontrando) nos horizontes africanos maior liberdade criativa, longe do braço duro da ditadura.

Em África, esses arquitectos obtêm reconhecimento e encomendas, numa primeira fase do sector privado e, mais tarde, com o fim do Gabinete de Urbanismo do Ultramar, junto ao sector público. A conjuntura política, económica e social altera-se nas colónias portuguesas: o número de portugueses que demandam África cresce substancialmente fazendo face ao impulso económico registado, dinamizando o tecido comercial e industrial. A conjugação do investimento entre estados e particulares no tecido produtivo leva ao aparecimento de uma classe média-alta disposta a demonstrar status e prestígio que procede a encomendas de autor, seja na construção de edifícios empresariais na implementação de conglomerados industriais com impacto na malha urbana e/ou rural ou habitações particulares, seja na construção de equipamentos de lazer para fazer frente à nascente indústria do turismo.

Esta prática resultante da encomenda de privados leva-os a adquirir "uma percepção integrada da realidade espacial dos problemas e necessidades que o contexto africano tinha e uma aura de prestígio e valia técnica que lhes permite assumir a execução dos Planos urbanísticos neste contexto específico" (MENDES, 2012, p. 199), que viria a ser aproveitada pela administração colonial.

A conjuntura política era nefasta para o regime, com os processos de descolonização a ocorrerem por todo o globo e aos quais Portugal não se consegue manter imune: a campanha internacional de que é alvo para promover uma descolonização e para que o país respeite os Direitos Humanos, a tensão com o governo indiano de Nehru visando às colónias de Goa, Damão e Diu (Estado Português da 
Índia), com sua consequente ocupação e anexação à União Indiana, associadas a alguma instabilidade política interna, obrigam a uma alteração artificial da posição do regime.

Essa situação abre caminho aos arquitectos modernistas radicados nas colónias portuguesas africanas, demonstrando uma abertura, mas igualmente procurando projectar internacionalmente uma aparência de normalidade e modernidade. Os arquitectos de outrora, se não ostracizados, pelo menos secundarizados pelos poderes políticos, são, então, procurados para intervir formalmente no tecido urbano das colónias. Essa inversão por parte do regime tem resultados práticos que se traduzem em planos nos quais a função da cidade é dominante, reflectindo um conhecimento das características e necessidades de cada espaço urbano:

em alguns casos o plano contemplava um esquema de vias de comunicação e um zonamento esquemático de funções, noutros casos aprofundava o desenho urbano até propor soluções de pormenores, sendo estas soluções inspiradas a uma composição mais aberta do espaço e dos edifícios (BRUSCHI; LAGE, 2005, p. 49).

\section{modernismo como modelador da paisagem urbana em África}

A arquitectura modernista integrava-se simbioticamente à paisagem africana, denotando uma adaptabilidade às especificidades climáticas tropical, como demonstram diversas soluções e obras implementadas executadas pelas diversas potências coloniais nos seus territórios ultramarinos, nas quais "as suas realizações confirmam a adaptabilidade da arquitectura moderna a climas tropicais" (MILHEIRO, 2009, p. 68) e para as quais no universo português as referências "à arquitectura brasileira, uma das culturas arquitectónicas emergentes a partir dos anos quarenta, prova exactamente essa qualidade de aclimatação" (MILHEIRO, 2009, p. 68), com a propriedade de que quando transpostas para fora do claustrofóbico rectângulo português, "no seio de uma sociedade menos restritiva e mais distante do centro do poder, o que estes arquitectos tiveram em comum foi essa possibilidade de construir com um vocabulário moderno" (MAGALHÃES; GONÇALVES, 2009, p. 18), através da apropriação e incorporação na sua obra "da universalidade e do dogmatismo do ideário moderno - o que lhes justifica a capacidade, contraria esses princípios, de adaptação às especificidades do lugar [...]" (MAGALHÃES; GONÇALVES, 2009, p. 18).

A contribuição dos arquitectos modernistas portugueses reflecte-se nas plantas, por exemplo, nas tentativas para se romper com a "ditadura" de se "construir/planificar de acordo com a rigidez da malha ortogonal seja através de transformações na própria malha, seja através de áreas de ruptura na sua periferia, procurando, no entanto, respeitar a integridade das preexistências" (MENDES, 2012, p. 199).

As marcas modernistas desses (e doutros arquitectos) são imensas, quer ao nível do urbanismo, quer da arquitectura em geral, estando ainda por efectuar um trabalho sistemático de levantamento e catalogação do património arquitectónico nas ex-colónias portuguesas, que se torna urgente pela forte dinâmica da construção civil registada em Angola e Moçambique. As marcas modernistas na África Portuguesa atestam o percurso dos arquitectos que intervencionaram o território, que dentre as diversas influências que beberam existe um papel determinante dos conceitos da arquitectura modernista brasileira, de tal forma que "Portugal foi assim o 'caso único' de uma nação com regime político retrógrado a nível europeu que teve uma produção de vanguarda inovadora no seu espaço colonial africano" (FERNANDES, 2000, p. 31).

Importa igualmente reflectir e contextualizar geograficamente a assimilação do modernismo colonial português com o impacto que a produção brasileira teve na região, nomeadamente na África do Sul, que influenciaria a produção em Angola e, especialmente, no vizinho Moçambique. Os ensinamentos do modernismo brasileiro foram divulgados e assimilados desde cedo na África do Sul, em especial em Joanesburgo e Pretória. Os alunos de arquitectura, tal como em Portugal a linha modernista, tinha como livro guia o catálogo Brazil Builds, que se disseminou pelos câmpus logo em 1943, altura, aliás, em que nasce a Faculdade de Arquitectura de Pretória, na qual Brazil Builds é adoptado como cânone (PEROLD, 2009, p. 43). A produção arquitectónica dentro da linha brasileira é fervilhante, encontrando-se marcos por toda a paisagem urbana do Transvaal, de tal forma que logo em 1953 Nikolaus Pevsner refere-se à cidade de Joanesburgo como 
"a little Brazil within the Common wealth" (apud PEROLD, 2009, p. 43). Essa ligação sul-africana com o modernismo brasileiro não se deve perder em virtude da proximidade geográfica e do impacto cultural dos maiores territórios portugueses e daqueles onde mais se fizeram sentir as experiências modernistas. Importa proceder a estudos comparativos que possam sustentar a influência nos arquitectos portugueses a trabalhar na África Portuguesa, alguns dos quais se formando em universidades do Transvaal ("Pancho" Guedes será o que mais se destaca), onde mais se observam as influências do modernismo brasileiro.

\section{A marca dos autores na paisagem} urbana em Moçambique e Angola

Francisco Castro Rodrigues (n. 1920) tem um percurso que lhe permite proceder a uma crítica conducente à ruptura pela prática instituída pela arquitectura de estado. Se a teoria bebe-a nas teses do CIAM - tendo sido um dos tradutores para português da Carta de Atenas, Rodrigues esteve igualmente ligado à revista Arquitectura (1947-1954) -, a prática inicia-a no Gabinete de Urbanismo Colonial e posteriormente do ateliê de João Simões, de quem subscreve as teses apresentadas no Congresso de Arquitectura de 1948 (MILHEIRO, 2008, p. 4). Estabelece-se em Angola, no Lobito, onde produz uma vasta obra que não renega a influência brasileira. Aliás, Francisco Castro Rodrigues será responsável pelo Núcleo de Estudos Angolano-Brasileiros, organizando uma exposição sobre A Arquitectura Moderna Brasileira, que palmilhará várias províncias de Angola (MILHEIRO, 2008, p. 8), assim como sua produção extravasa cada vez mais o Lobito.

Se no Lobito, a paisagem urbana se confunde com a produção de um arquitecto em Moçambique, a paisagem urbana da cidade da Beira conhece intensa actividade criativa, pontuando vários arquitectos que deixariam sua marca num dos espaços mais surpreendentes do universo urbano colonial lusófono. Nomes como Paulo de Melo Sampaio, João Garizo do Carmo, Francisco Castro (os três assinariam o projecto da Estação de Caminho-de-Ferro da Beira)
(Figuras 5, 6 e 7), Carlos Ivo, Bernardino Ramalhete ou Eduardo Naia, entre outros, produziram suas principais obras naquela cidade, dotando-a de um carácter modernista que não se esgota numa única leitura, tal o número de abordagens estéticas e o experimentalismo, no âmbito da engenharia civil, que provocaram num solo pouco próprio para a construção.

Declaradamente modernistas, a influência brasileira é notória, existindo casos de (aparente) inspiração directa de obras produzidas em solo brasileiro. Foi o caso de João Garizo do Carmo, com uma de suas obras mais emblemáticas: a igreja da Manga (Beira, Moçambique) com fortes semelhanças inspiracionais com a igreja de S. Francisco de Assis, na Pampulha (Brasil), de Oscar Niemeyer. Ao nível do urbanismo, Paulo de Melo Sampaio, a par de obras de arquitectura marcante, foi responsável pela elaboração de diversos Planos de Pormenor (Macúti/ Beira) e de Urbanização (Vila Pery/Chimoio, Nacala, Porto Amélia/Pemba) (MAGALHÃES; GONÇALVES, 2009, p. 200). Também Bernardino Ramalhete, com um percurso ligeiramente diferente dos seus colegas, assinaria vários Planos de Urbanismo (Nampula, António Enes/Angoche e Vila Pery/Chimoio), mas é na Beira e nos projectos que executou que se lhe reconhece o traço ${ }^{4}$.

Ainda na Beira, cidade de múltiplos mistérios arquitectónicos, uma referência a um edifício que por si só constitui uma marca na paisagem urbana e um marco na arquitectura portuguesa: o Grande Hotel da Beira (Figura 8). É um projecto de traço modernista, da responsabilidade de José Porto e Francisco Castro, construído para ser um símbolo da cidade. Implantado junto ao mar num terreno com 12 mil m2, onde, além do edifício do Hotel, com 125 quartos, incluía-se uma piscina olímpica e um casino. Iniciadas as obras em 1953, foram concluídas em 1955, um ano depois do previsto e com uma enorme derrapagem financeira, triplicando os custos iniciais. 0 Hotel encerrou dois anos após a inauguração, por falta de clientela e por não ter sido autorizada a abertura do casino, que seria o garante do projecto. Actualmente, residem nas estruturas muito degradadas do "Hotel" cerca de 3 mil pessoas, que aqui encontraram refúgio da guerra civil que assolou o país.

\footnotetext{
4 Fora dessa cidade é de assinalar a Biblioteca de Quelimane, considerada obra de grande importância no património arquitectónico moçambicano.
} 


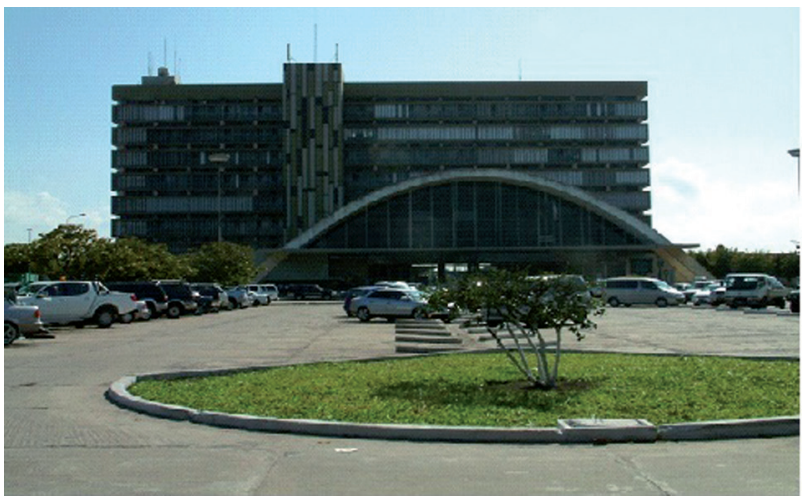

Figura 5 - Estação de Caminho-de-Ferro da Beira, projecto dos arquitectos Paulo de Melo Sampaio Sampaio, João Garizo do Carmo, Francisco Castro Fonte: Rui Paes Mendes, 2011.

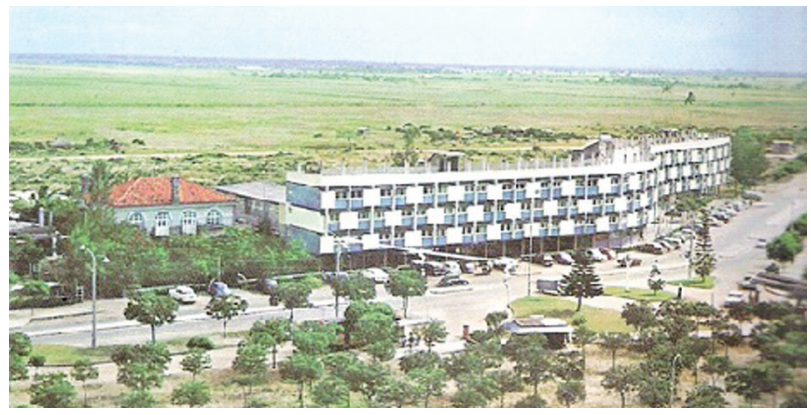

Figura 6 - Motel Estoril, Macúti (1965), projecto do arquitecto Paulo Melo Sampaio

Fonte: LOUREIRO, 2001

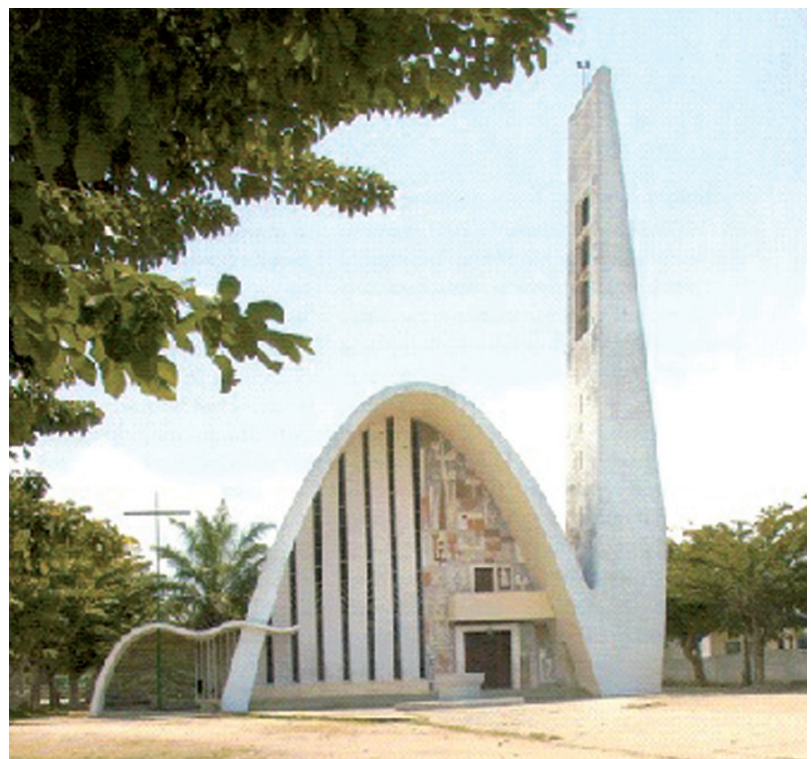

Figura 7 - Igreja da Manga (2009), projecto do arquitecto João Garizo do Carmo

Fonte: MAGALHÃES; GONCALVES, 2009.
De entre os diversos planos urbanísticos efectuados por arquitectos modernistas damos como exemplo o caso de Paulo Melo Sampaio, para Porto Amélia/ Pemba (Figura 9), como ilustração das abordagens espaciais para as cidades durante o período correspondente à década de 1960. É um plano que mantém as características de zonamento racial, não existindo aqui nenhuma ruptura com a prática anterior. Procura-se efectuar uma transformação na grelha ortogonal, introduzindo e anexando "áreas de composição aberta, com sistemas de eixos urbanos hierarquizados, utilizando tipologias mais complexas que a moradia unifamiliar então preferida" (BRUSCHI; CARRILHO; LAGE, 2005, p. 49). Procura-se igualmente proceder a uma transformação nas áreas destinadas aos bairros informais, regulando-os e/ou transpondo-os para outros espaços, mas com uma nova filosofia menos segregacionista ao nível racial: são substituídos por zonas destinadas a construções de baixo custo de características multiculturais e multirraciais.

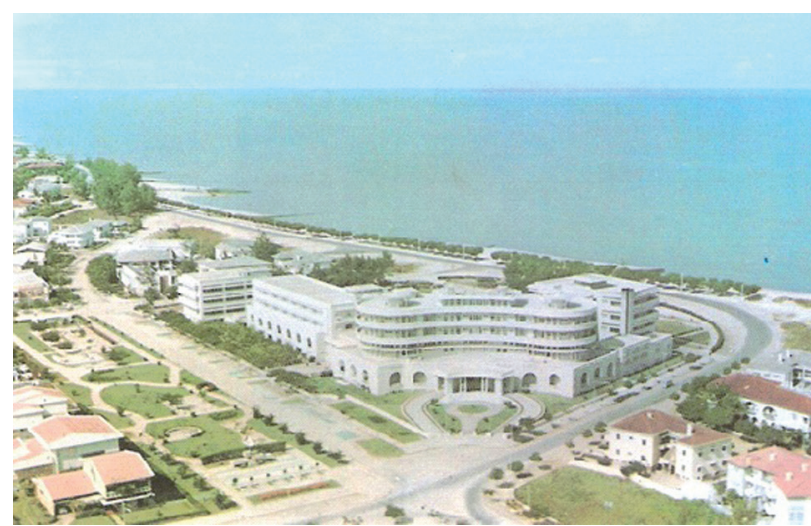

Figura 8 - Grande Hotel da Beira (c. 1957), projecto do arquitecto José Porto Fonte: LOUREIRO, 2001.

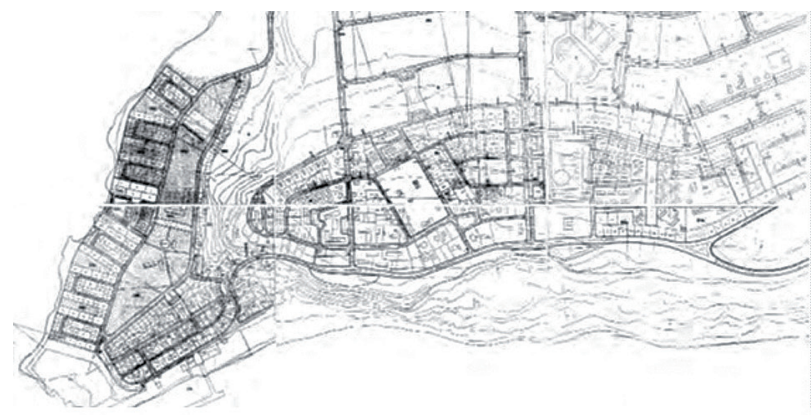

Figura 9 - Plano de Urbanização de Porto Amélia/Pemba, arquicteto Paulo de Melo Sampaio, (1965-1967)

Fonte: BRUSCHI; CARRILHO; LAGE, 2005. 
No entanto, esse tipo de intervenção urbana depara-se com fortes constrangimentos, que impedem sua cabal concretização em virtude de questões jurídicas relacionadas com a posse da terra/propriedade e antagonismo dos proprietários à aplicação do Plano.

Num quadrante oposto ao nível da formação, mas nem por isso distante do imaginário modernista brasileiro, e com uma obra que desafia todas as convenções e profundamente actual, o trabalho de "Pancho" Guedes em Moçambique, mais concretamente em Maputo, marcaria de forma indelével a paisagem da cidade (Figura 10). Sua formação de base difere da dos restantes arquitectos portugueses pelas influências que bebeu (também) em consequência de ter estudado na África do Sul, na Universidade de Witwatersrand - Joanesburgo, onde se perspectivava uma arquitectura diferenciada daquelas definidas na academia portuguesa, mas igualmente muito próxima daquilo pelos quais os formados na sua universidade ficariam conhecidos por produzir: Little Brazil. Apesar do périplo que efectua pelo Brasil, onde visita obras emblemática e divulga seu trabalho (MILHEIRO, 2008, p. 12), sua obra absorve e sintetiza elementos característicos da sociedade e cultura moçambicanas, reflectindo criações aparentemente populares mas formalmente complexas e imaginativas.

Finalmente um último nome, essencialmente simbólico pelo périplo a que nos propusemos fazer com o presente artigo: Fernão Simões de Carvalho, arquitecto e urbanista com uma produção legada a Angola. Tendo estudado em Lisboa, passa pelo Gabinete de Urbanismo Colonial, seguindo para

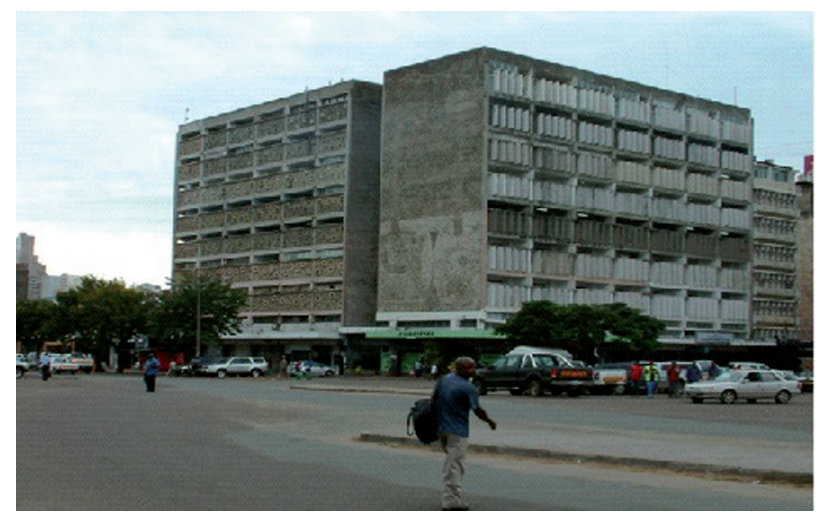

Figura 10 - Edifício Abreu, Santos e Rocha, arquitecto "Pancho Guedes" Fonte: Rui Paes Mendes, 2011. o ateliê de Le Corbusier, no qual exerce arquitectura, entre 1955 e 1959 (tem participação directa nos projectos do convento de La Tourette, nas Unités d'Habitacion de Berlim e Briey-en-Fôret e no Pavilhão do Brasil da Cidade Universitária de Paris), ano no qual embarca para Angola, onde tem a sua actividade em Luanda. Regressa a Lisboa em 1967, mas seu périplo profissional não terminaria na capital portuguesa: de 1977 a 1979 trabalha no Brasil, conduzindo projectos na área do urbanismo, finalizando posteriormente sua carreira em Portugal (MAGALHÃES; GONÇALVES, 2009, p. 196-197).

Muitos outros nomes e obras emblemáticas do modernismo colonial português, influenciado pelo Brasil, poderiam ser referenciados numa área na qual muito (quase tudo?) se encontra por fazer, pois os levantamentos nas antigas colónias portuguesas são diminutos e limitados pelos custos e dimensão geográfica. 0 certo é que ainda muito está por descobrir, classificar e divulgar em territórios que não cessam de surpreender pela diversidade, imaginação e riqueza arquitectónica e urbanística, que não se limitam a ideias pré-concebidas ou estereótipos que urge quebrar.

\section{Referências}

BRUSCHI, S.; CARRILHO, J.; LAGE, L. Pemba: as duas cidades. Maputo: FAPF, 2005.

BRUSCHI, S.; LAGE, L. M. O desenho das cidades, Moçambique até o século XXI. Maputo: FAPF, 2005.

FERNANDES, J. M. Geração africana. Jornal Expresso, Lisboa, jan. 2000.

FERNANDES, J. M; ALMEIDA, P. V. História da arte em Portugal, arquitectura moderna. Lisboa: Publicações Alfa, 1993. v. 14.

FERNANDES, M. G. Urbanismo e morfologia urbana no Norte de Portugal - 1852/1926. Porto: Faculdade de Letras da Universidade do Porto, 2001.

LOUREIRO, J. Moçambique. Lisboa: João Loureiro e Associados, 2001.

MAGALHÃES, A.; GONÇALVES, I. Moderno tropical, arquitectura em Angola e Moçambique, 1948-1975. Lisboa: Tinta-da-China, 2009. 
MENDES, R. P. A Cidade colonial e a estruturação do território em Moçambique: a evolução urbana de Lourenço Marques/Maputo, Beira, Nampula e Porto Amélia/Pemba. 2012.518f. Tese (Doutorado em Geografia Humana) - Faculdade de Letras da Universidade do Porto, Porto, 2012.

MILHEIRO, A. C. F. V.; FERREIRA, J. M. F. F. A Joyous Architecture: as exposições de arquitectura moderna brasileira em Portugal e a sua influência nos territórios português e africano. [200-]. Disponível em <http:// www.docomomo.org.br/seminario\%208\%20pdfs/018. pdf>. Acesso em: 12 de maio de 2011.

MILHEIRO, A. V.; DIAS, E. C. Arquitectura em Bissau e os gabinetes de urbanização colonial (1944-1974). Revista eletrônica de Arquitetura e Urbanismo, n. 2, p. 80-114, 2009.

MILHEIRO, A. V. Experiências em concreto armado na África portuguesa: influências do Brasil. Pós - Revista do Programa de Pós-Graduação em Arquitetura e Urbanismo, v. 16, n. 25, p. 56-79, jun. 2009.

MILHEIRO, A. V. As coisas não são o que parecem ser. Porto: Dafne Editora, 2008.

MOÇAMBIQUE: DOCUMENTÁRIO TRIMESTRAL. Lisboa: Memória de Africa, n. 001, mar. 1935. 157 p.
MONIZ, G. C. Arquitectos e políticos. A arquitectura institucional em Portugal nos anos 30. DC Papeles, n. 13/14, p. 68-79, out. 2005.

PEROLD, M. Music2 - extension and conversion of the Department of Music of the University of Pretoria. 2009. 138 f. Dissertação (Mestrado em Arquitetura professional) - Faculdade de Engenharia, Ambiente Construído e Tecnologia da Informação, Universidade de Pretoria, Pretoria, 2009.

PORTUGAL. Decreto n. 34.173, de 6 de dezembro de 1944. Procede à criação e definição dos desígnios do Gabinete de Urbanismo Colonial. Diário de Governo: Lisboa, 1944.

SINDICATO NACIONAL DOS ARQUITECTOS. Actas do $\mathbf{1}^{\mathbf{o}}$ Congreso Nacional de Arquitectura. Lisboa: Sindicato Nacional dos Arquitectos, 1948.

TOSTÕES, A. Arquitectura portuguesa do século XX. In: PEREIRA, P. (Dir.). História da Arte Portuguesa. Lisboa: Temas e Debates. 1999. v. 3.
Recebido: 30/05/2012

Received: 05/30/2012

Aprovado: $16 / 10 / 2012$

Approved: 10/16/2012 